\title{
Hemophagocytic Lymphohistiocytosis Caused by Pyogenic Liver Abscess during Pregnancy: A Case Report and Literature Review
}

\author{
Kanako Ota1, Kazumi Kawahara1, Harumichi Banno1, \\ Koji Nishijima², Yoshio Yoshida2* \\ ${ }^{1}$ Department of Obstetrics and Gynecology, Maizuru Kyosai Hospital, Kyoto, Japan \\ ${ }^{2}$ Department of Obstetrics and Gynecology, Faculty of Medical Sciences, University of Fukui, Fukui, Japan \\ Email: c.aoba.taki.tsu@gmail.com, kamiko@mountain.ocn.ne.jp, prototype-4-gerbera@hotmail.co.jp, \\ kojigyne@u-fukui.ac.jp, ”yyoshida@u-fukui.ac.jp
}

Received 17 March 2016; accepted 23 April 2016; published 26 April 2016

Copyright (C) 2016 by authors and Scientific Research Publishing Inc.

This work is licensed under the Creative Commons Attribution International License (CC BY). http://creativecommons.org/licenses/by/4.0/

(c) (i) Open Access

\begin{abstract}
Introduction: Hemophagocytic lymphohistiocytosis during pregnancy is a rare and severe condition, and timely diagnosis is quite difficult. We present the first case of hemophagocytic lymphohistiocytosis caused by pyogenic liver abscess during pregnancy and discuss the clinical presentation. Case Presentation: A 26-year-old Japanese primigravida at 23 weeks of gestation complained of extremely high fever with a fast heart rate (140 beats per minute). She presented with systemic inflammatory response syndrome (SIRS). Only 2 days later, she died. Autopsy findings proved that this was the first case of hemophagocytic lymphohistiocytosis caused by pyogenic liver abscess during pregnancy. Conclusion: Hemophagocytic lymphohistiocytosis should be considered when patients meet the SIRS criteria, especially whose clinical presentation includes extremely high fever $\left(39^{\circ} \mathrm{C}\right)$ and a fast heart rate (greater than $110 \mathrm{bpm}$ ) during pregnancy, despite relatively normal laboratory data, because such vital signs may be associated with the onset of hemophagocytic lymphohistiocytosis.
\end{abstract}

\section{Keywords}

Hemophagocytic Lymphohistiocytosis, Pregnancy, SIRS, Sepsis, Pyogenic Liver Abscess

\footnotetext{
${ }^{*}$ Corresponding author.

How to cite this paper: Ota, K., Kawahara, K., Banno, H., Nishijima, K. and Yoshida, Y. (2016) Hemophagocytic Lymphohistiocytosis Caused by Pyogenic Liver Abscess during Pregnancy: A Case Report and Literature Review. Open Journal of Obstetrics and Gynecology, 6, 287-292. http://dx.doi.org/10.4236/ojog.2016.65036
} 


\section{Introduction}

Hemophagocytic lymphohistiocytosis (HLH) is a disorder characterized by histiocyte activation associated with a hyperinflammatory state and phagocytosis of hematopoietic elements [1]. The major clinical manifestations of HLH are fever and hepatosplenomegaly, however, less frequently observed are rash, lymphadenopathy, icterus and neurologic symptoms. The pathogenesis was based on both inherited and acquired HLH is impaired cytolytic function of natural killer (NK) cells and CD8+. In HLH-2004, diagnosis was based on five criteria (fever, splenomegaly, bicytopenia, hypertriglyceridemia and/or hypofibrinogenemia, and hemophagocytosis) and three additional criteria are introduced; low/absent NK-cell-activity, hyperferritinemia, and high-soluble interleukin-2receptor levels. HLH is often associated with infections, autoimmune disorders, or malignancies, such as lymphomas. HLH is a rare, life-threatening inflammatory disorder. Currently, recommended therapy for HLH such as the HLH-2004 was established; however, these regimens were not safe in pregnancy.

HLH in pregnancy presents uncommon clinical dilemma, because there are quite less effective treatments for such as patients especially with pyogenic liver abscess. Thus, outcome of HLH in pregnancy is quite poor. Timely diagnosis of HLH in pregnant women is important but quite difficult. The case of a pregnant woman at 24 weeks of gestation who died 2 days after being admitted with fever and a systemic inflammatory response syndrome (SIRS) is presented. Autopsy findings proved this to be a rare case of HLH caused by pyogenic liver abscess.

\section{Case Presentation}

A 26-year-old Japanese primigravida had an uneventful pregnancy until 22 weeks of gestation. The patient's medical history and family history were unremarkable. At 23 weeks of gestation, she complained of nausea and fever as high as $39^{\circ} \mathrm{C}$ for 2 days. She was given intravenous fluid as an outpatient. The next day, she returned to the hospital because her symptoms persisted. At the time, her temperature was $40.8^{\circ} \mathrm{C}$, her pulse was 140 beats per minute (bpm), and her blood pressure was 106/62 mmHg. Her consciousness was clear, and she did not have any symptoms such as headache, abdominal pain, dysuria, diarrhea, sore throat, or cough. On ultrasound, she had a healthy fetus of 23 weeks of gestation. Physical examination revealed no tenderness of the abdomen, clear lung fields, and no abnormal findings. The cervical examination was also normal. Laboratory studies showed: white blood cell $5.7 \times 10^{9} / \mathrm{l}$ (normal range $4.0 \times 10^{9} / \mathrm{l}-10.0 \times 10^{9} / \mathrm{l}$ ), hemoglobin $126 \mathrm{~g} / \mathrm{l}$ (normal range, 113 $149 \mathrm{~g} / \mathrm{l}$ ); platelets (Plt) $66 \times 10^{9} / \mathrm{l}$ (normal range, $163 \times 10^{9} / \mathrm{l}-428 \times 10^{9} / \mathrm{l}$ ); and C-reactive protein (CRP) 7.26 $\mathrm{mg} / \mathrm{dl}$ (normal range $0-0.6 \mathrm{mg} / \mathrm{dL}$ ). Serum aspartate transaminase (AST) (normal range 8 - $46 \mathrm{IU} / \mathrm{L}$ ) and alanine transaminase (ALT) (normal range 0 - $35 \mathrm{IU} / \mathrm{L}$ ) as measures of liver function were $115 \mathrm{IU} / \mathrm{L}$ and $203 \mathrm{IU} / \mathrm{L}$. Her lactate dehydrogenase was $389 \mathrm{IU} / \mathrm{L}$ (normal range 120 - $240 \mathrm{IU} / \mathrm{L}$ ). Blood and uterine cultures were taken. The plan was to observe the patient in the hospital with rehydration therapy.

However, on hospital day 2, the patient suddenly lost consciousness. Her temperature was $40.2^{\circ} \mathrm{C}$, her pulse was $150 \mathrm{bpm}$, her blood pressure was 130/80 $\mathrm{mmHg}$, and $\mathrm{SpO}_{2}$ was $88 \%$. On ultrasound, intrauterine fetal death was confirmed. The patient was given oxygen. During survey brain magnetic resonance imaging (MRI), the patient developed cardiopulmonary arrest. Cardiopulmonary resuscitation with administration of adrenaline was attempted, but the patient died. The laboratory studies when she lost consciousness showed leukopenia, thrombocytopenia, hepatic dysfunction, renal dysfunction, hyperferritinemia, and disseminated intravascular coagulation. The blood and urine cultures taken during her hospital stay were negative. Brain MRI was normal.

Autopsy imaging did not reveal any cause of death. Finally, autopsy revealed a pyogenic liver abscess caused by anaerobic Gram-positive bacilli and significantly increased histiocytes with active hemophagocytosis in her bone marrow (Figure 1).

Viral studies for cytomegalovirus, Ebstein-Barr virus, herpes simplex virus, human immunodeficiency virus, parvovirus B19, rubella, and hepatitis A and B were all negative. These findings resulted in a diagnosis of HLH associated with pyogenic liver abscess based on the HLH 2004 diagnostic criteria [1].

\section{Discussion}

The PubMed and MEDLINE databases were searched for relevant, English-language articles. Search terms included "hemophagocytic lymphohistiocytosis" and "hemophagocytic syndrome", in association with "pregnancy”. After abstract review, cases were selected for full text evaluation from 1991 to 2015. It was found that HLH 


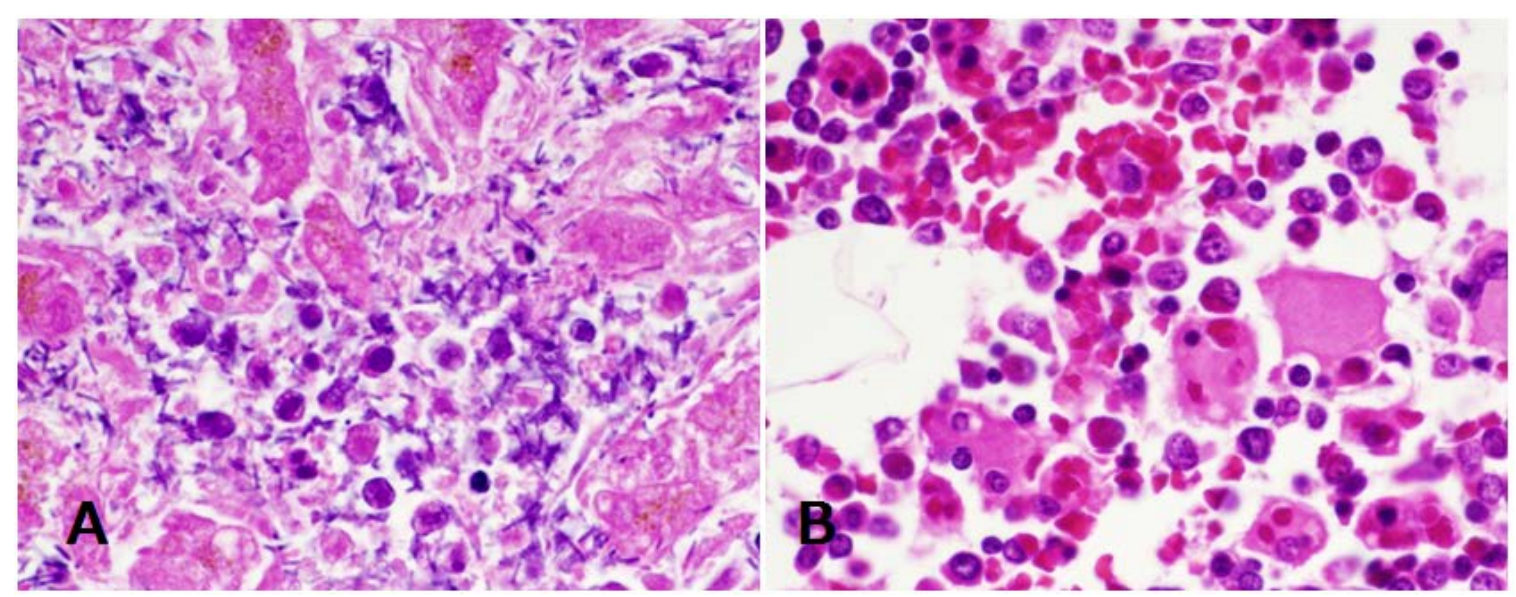

Figure 1. Autopsy findings, (A) Liver abscess by anaerobic Gram positive bacillus, (B) Histiocytes with hemophagocytosis in her bone marrow. Both of them were Hematoxyline and Eosin staining. Scale bars, $50 \mu \mathrm{m}$.

during pregnancy has been reported in only 9 cases, including the present case, in the English literature (Table 1).

The disease underlying HLH was Epstein-Barr virus infection in 2 cases, herpes simplex virus-2 infection in 1 case, parvovirus B19 infection in 1 case, and malignant lymphoma in 1 case. This is the first case report of HLH caused by a pyogenic liver abscess.

There are several diagnostic criteria for HLH. Criteria modified from Henter et al. have been widely used, although these criteria were mainly composed of data of pediatric HLH cases. Diagnosis of HLH can be made with fever, splenomegaly, unexplained cytopenia affecting at least 2 cell lines, hypertriglyceridemia or hypofibrinogenemia, hemophagocytosis in bone marrow, spleen, or lymph nodes, low or absent natural killer cell activity, ferritin $500 \mathrm{ng} / \mathrm{mL}$ or more, and elevated soluble CD25 (soluble interleukin-2 receptor) [1].

According to published reports, bone marrow biopsy was performed for the differential diagnosis of cytopenia, and the detection of hemophagocytosis in bone marrow was considered supportive of a diagnosis. However, Mayama et al. pointed out that this is not sensitive enough to support a definitive diagnosis, and that this method is aggressive; this method must especially be considered for pregnant women with a high fever. Mayama et al. also pointed out that measuring levels of soluble interleukin-2 receptors (sCD25) is certainly more specific than other diagnostic criteria, because these tests are based on the pathogenesis of HLH. However, in many cases, these assays must be done by an outside commercial laboratory, as is done for killer cell activity [2]. Thus, previous reports showed that the average number of days to make the diagnosis of HLH was 17 days, not including the present case. In the present case, the patient died only two days after she was admitted. It is also important to note that, with respect to prognosis, in 3 of 10 cases, including the present case, the mother and fetus died, and in 3 of the 10 cases, the fetus died in utero. HLH during pregnancy has a maternal mortality rate of around 30\%. This high mortality rate indicates the importance of timely diagnosis of this condition, especially in pregnant women [3].

Thus, it is important to consider whether there are any symptoms or signs that are highly suggestive of HLH. Previous reports showed that 7 of 10 cases, including the present case the other 3 cases were incomplete) met the SIRS criteria, especially with an extremely high fever and a fast heart rate.

The American College of Chest Physicians and the Society of Critical Care Medicine define sepsis as SIRS secondary to infection. Two of the following four criteria must be present to meet the SIRS criteria: temperature greater than $38^{\circ} \mathrm{C}$ or less than $36^{\circ} \mathrm{C}$; respiratory rate greater than $20 \mathrm{bpm}$ or $\mathrm{PaCO}_{2}$ less than $32 \mathrm{~mm} \mathrm{Hg}$; heart rate greater than $90 \mathrm{bpm}$; or WBC count greater than $12 \times 109 / \mathrm{L}$ or less than $4 \times 109 / \mathrm{L}$, or bands greater than $10 \%[4]$.

As for pregnant women, Bauer et al. reported that the normal ranges for physiologic and laboratory parameters during pregnancy and immediately postpartum overlap substantially with the SIRS criteria. For example, values for respiratory rate, $\mathrm{PaCO}_{2}$, heart rate, and WBC count during normal pregnancy meet the criteria, thus reducing the specificity and use of these indices for diagnosing sepsis in pregnant and postpartum women [5]. Regarding maternal heart rate, although there is a physiologic increase in the heart rate of pregnant women, a 


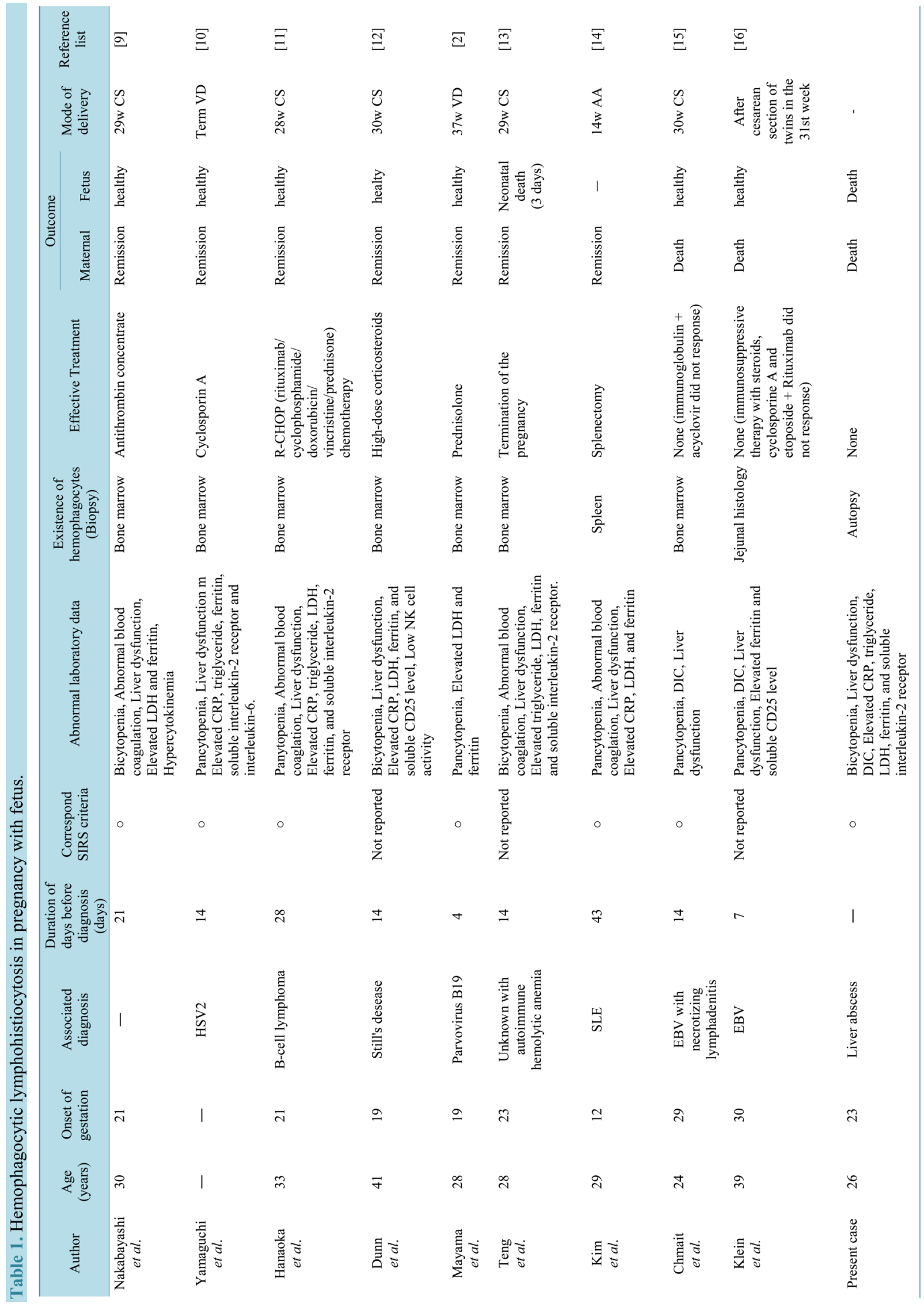


higher threshold for the heart rate may be needed to identify sepsis, as recommended by Barton and Sibai, who suggest sepsis evaluation at heart rates greater than $110 \mathrm{bpm}$ in pregnant women [6].

The SIRS criteria, especially an extremely high fever and a fast heart rate, may help identify suspected HLH. The present case initially showed a SIRS clinical presentation with a high-grade fever (more than $40^{\circ} \mathrm{C}$ ) and a fast tachycardia (greater than $140 \mathrm{bpm}$ ); retrospectively, this presentation is highly suggestive of sepsis even in the presence of relatively normal laboratory data, as seen in other cases. It is also worth noting that evaluation of HLH during pregnancy might be complicated by similarities to HELLP syndrome. Both disorders can present with anemia caused by hemolysis,elevated liver enzymes, and thrombocytopenia. Absence of hypertension and proteinuria have been documented in HELLP, but HELLP usually improves within several days of delivery, whereas HLH is progressive [7].

Pyogenic liver abscess (PLA) is a serious and life-threatening condition. Although fever and right upper quadrant abdominal pain are known to be the most common symptoms, the clinical presentation in many cases is nonspecific and is difficult to diagnose. In addition, PLA during pregnancy is extremely rare. PLA during pregnancy has been reported in only 3 cases, including the present case, in the English literature for which full text is available [8]. Since the clinical and laboratory findings are usually nonspecific, and this condition is rare in pregnant women, a misdiagnosis is likely, but early diagnosis and therapy are vital because of the high mortality rate in untreated cases. In particular, PLA onset in pregnancy may show acute progression to severe sepsis or septic shock associated with multiple organ dysfunction syndrome and death, as in the present case.

At presentation, the current patient had a normal blood pressure, high fever, and a fast tachycardia. The initial laboratory data showed a normal WBC count and no anemia, but CRP was elevated, and liver enzymes were also moderately elevated. These findings did not suggest the need for a more aggressive diagnostic approach, such as whole-body ultrasound and Computed Tomography (CT). Thus, the patient was treated as having a severe infection of unknown origin.

Treatments for HLH during pregnancy are summarized in Table 1, which shows that successful treatment of HLH depends on the timing of diagnosis, number of gestational weeks, causative factor, and prompt initiation of treatment. Timely diagnosis, relatively early pregnancy, and viral infection as the cause seem related to a good clinical course. Prompt treatment with high dose IV immunoglobulin (Ig), glucocorticoid, cyclosporine A, and cytotoxic drugs has been reported. If this case had been diagnosed as a rare case of HLH caused by pyogenic liver abscess before the patient died, ultrasound-guided percutaneous aspiration and drainage with sterile saline may have been effective.

Although rare cases of sepsis in pregnancy, the possibility of a liver abscess should be kept in mind. The physician should consider a more aggressive approach to diagnosis, such as whole-body CT, or ultrasound evaluation of whole body.

\section{Conclusion}

This is the first case of HLH caused by PLA during pregnancy. The clinical course was quite rapid and fatal, and the diagnosis was also quite difficult. We must pay attention to an extremely high fever and high heart rate (140 bpm) during pregnancy, even with relatively normal laboratory data, as they may be associated with the onset of sepsis. The physician should consider a more aggressive approach to diagnosis, such as whole-body CT, but with modified diagnostic criteria for pregnant women. Timely diagnosis and prompt treatment are vital.

\section{Consent}

Written informed consent was obtained from the patient for publication of this case report and accompanying images. A copy of the written consent is available for review by the Editor-in-Chief of this journal.

\section{Competing Interests}

The authors declare that they have no competing interests.

\section{Authors' Contributions}

KO drafted the manuscript and KK and YY assessed the quality of the paper. KO, HB and KK treated the patient. KK, KN and YY revised the manuscript critically for its content. All authors read and approved the final 
manuscript.

\section{References}

[1] Henter, J.I., Horne, A., Aricó, M., Egeler, R.M., Filipovich, A.H., Imashuku, S., Ladisch, S., McClain, K., Webb, D., Winiarski, J. and Janka, G. (2007) HLH-2004: Diagnostic and Therapeutic Guidelines for Hemophagocytic Lymphohistiocytosis. Pediatric Blood \& Cancer, 48, 124-131. http://dx.doi.org/10.1002/pbc.21039

[2] Mayama, M., Yoshihara, M., Kokabu, T. and Oguchi, H. (2014) Hemophagocytic Lymphohistiocytosis Associated with a Parvovirus B19 Infection during Pregnancy. Obstetrics \& Gynecology, 124, 438-441. http://dx.doi.org/10.1097/AOG.0000000000000385

[3] Bone, R.C., Balk, R.A., Cerra, F.B., Dellinger, R.P., Fein, A.M., Knaus, W.A., et al. (1992) Definitions for Sepsis and Organ Failure and Guidelines for the Use of Innovative Therapies in Sepsis. The ACCP/SCCM Consensus Conference Committee. American College of Chest Physicians/Society of Critical Care Medicine. Chest, 101, 1644-1655. http://dx.doi.org/10.1378/chest.101.6.1644

[4] Bauer, M.E., Bauer, S.T., Rajala, B., MacEachern, M.P., Polley, L.S., Childers, D. and Aronoff, D.M. (2014) Maternal Physiologic Parameters in Relationship to Systemic Inflammatory Response Syndrome Criteria: A Systematic Review and Meta-Analysis. Obstetrics \& Gynecology, 124, 535-541. http://dx.doi.org/10.1097/AOG.0000000000000423

[5] Barton, J.R. and Sibai, B.M. (2012) Severe Sepsis and Septic Shock in Pregnancy. Obstetrics \& Gynecology, 120, 689-706. http://dx.doi.org/10.1097/AOG.0b013e318263a52d

[6] Chmait, R.H., Meimin, D.L., Koo, C.H. and Huffaker, J. (2000) Hemophagocytic Syndrome in Pregnancy. Obstetrics \& Gynecology, 95, 1022-1024. http://dx.doi.org/10.1097/00006250-200006001-00010

[7] Yüksel, B., Seven, A., Kucur, S., Gözükara, I. and Keskin, N. (2013) Presentation and Management of Pyogenic Liver Abscess in a 23-Week Pregnant Woman. Case Reports in Obstetrics and Gynecology, 845215. http://dx.doi.org/10.1155/2013/845215

[8] Kopernik, G., Mazor, M., Leinberman, J.R., Barki, Y. and Hirsch, M. (1988) Pyogenic Liver Abscess in Pregnancy Isr. Journal of Medical Science, 24, 245-246.

[9] Nakabayashi, M., Adachi, T., Izuchi, S. and Sugisaki, A. (1999) Association of Hypercytokinemia in the Development of Severe Preeclampsia in a Case of Hemophagocytic Syndrome. Seminars in Thrombosis and Hemostasis, 25, 467471. http://dx.doi.org/10.1055/s-2007-994952

[10] Yamaguchi, K., Yamamoto, A., Hisano, M., Natori, M. and Murashima, A. (2005) Herpes Simplex Virus 2-Associated Hemophagocytic Lymphohistiocytosis in a Pregnant Patient. Obstetrics \& Gynecology, 105, 1241-1244. http://dx.doi.org/10.1097/01.AOG.0000157757.54948.9b

[11] Hanaoka, M., Tsukimori, K., Hojo, S., Abe, Y., Mutou, T., Muta, K., Iwasa, A., Yao, T. and Nakano, H. (2007) B-Cell Lymphoma during Pregnancy Associated with Hemophagocytic Syndrome and Placental Involvement. Clinical Lymphoma and Myeloma, 7, 486-490. http://dx.doi.org/10.3816/CLM.2007.n.033

[12] Dunn, T., Cho, M., Medeiros, B., Logan, A., Ungewickell, A. and Liedtke, M. (2012) Hemophagocytic Lymphohistiocytosis in Pregnancy: A Case Report and Review of Treatment Options. Hematology, 17, 325-328. http://dx.doi.org/10.1179/1607845412Y.0000000007

[13] Teng, C.L., Hwang, G.Y., Lee, B.J., Wang, R.C. and Chou, M.M. (2009) Pregnancy-Induced Hemophagocytic Lymphohistiocytosis Combined with Autoimmune Hemolytic Anemia. Journal of the Chinese Medical Association, 72, 156-159. http://dx.doi.org/10.1016/S1726-4901(09)70043-7

[14] Kim, J.M., Kwok, S.K., Ju, J.H., Park, K.S., Park, G.S., Kim, H.Y. and Park, S.H. (2013) Macrophage Activation Syndrome Resistant to Medical Therapy in a Patient with Systemic Lupus Erythematosus and Its Remission with Splenectomy. Rheumatology International, 33, 767-771. http://dx.doi.org/10.1007/s00296-010-1654-4

[15] Chmait, R.H., Meimin, D.L., Koo, C.H. and Huffaker, J. (2000) Hemophagocytic Syndrome in Pregnancy. Obstetrics \& Gynecology, 95, 1022-1024.

[16] Klein, S., Schmidt, C., La Rosée, P., Pletz, M., Harz, S., Dirsch, O., Fritzenwanger, M. and Stallmach, A. (2014) Fulminant Gastrointestinal Bleeding Caused by EBV-Triggered Hemophagocytic Lymphohistiocytosis: Report of a Case. Z Gastroenterologie, 52, 354-359. http://dx.doi.org/10.1055/s-0034-1366154 